\title{
LA NOVELA ESPAÑOLA DEL SIGLO XVIII: ESTADO DE LA CUESTIÓN (1985-1995)
}

\author{
Guillermo CARNERO \\ Universidad de Alicante
}

\section{ADVERTENCIA}

El propósito de estas páginas es presentar un informe y balance de lo mucho que, en la década que señala el título, se ha avanzado en el estudio y conocimiento de nuestra novela dieciochesca.

Ante la necesidad de acortar el período en consideración, reducirlo a los diez últimos años me ha parecido la mejor opción cuando intentaba conjugar la inevitable limitación de espacio con la delimitación de una zona temporal, significativa por haberse dado en ella una notable aceleración del ritmo de publicación de documentos y estudios concernientes al tema escogido. Salvo que sea necesario para la adecuada situación de aportaciones encuadradas en el decenio citado, no mencionaré las anteriores a 1985.

He pretendido que mi información fuera lo más completa posible, echando mano de mi propio archivo, repasando los repertorios bibliográficos y enviando una consulta circular a los dieciochistas que actualmente destacan por su dedicación al estudio de la novela, en la que les pedía que la corrigieran o completaran y me proporcionaran lista y resumen de sus trabajos en prensa. Todos los datos que he recibido, y que agradezco, han sido incorporados.

No se me oculta que la colisión entre la extensión plausible de este artículo y la amplitud del material que en él debo tener en cuenta (centenar y medio de entradas bibliográficas) me obliga a resúmenes muy sintéticos. Pero mi propósito es presentar un recuento panorámico y no sustituir el recurso a los estudios de interpretación, historiografía o crítica, o a las ediciones de textos. Si mis comentarios han de ser por fuerza ampliables y perfectibles, tendrán al menos, junto a la bibliografía que los acompaña, la utilidad de ofrecer ésta a los interesados en el tema, y la de hacer evidente que nuestra marginada y olvidada novela del XVIII está en vías de ser reconocida como un ámbito de contenido pleno e interés indudable en la historiografía literaria española. 
Mi enfoque no es sistemáticamente valorativo, y sólo adoptaré esa actitud en casos muy concretos. El no disponer de suficiente espacio para análisis detenidos daría a la intención valorativa, por necesidad insuficientemente probada, un aspecto de indeseable arbitrariedad.

En el caso de autores que, además de novela, practicaron otros géneros literarios, he excluido lo que concierne a estos últimos, pero no los estudios generales o biográficos. Excluyo igualmente el cajón de sastre de las formas narrativas no novelescas, las utopías y los viajes imaginarios. Incluyo textos considerados tradicionalmente novelescos, aunque esa adscripción sea parcial o discutible. No tengo en cuenta, por su fácil accesibilidad y por su habitual carácter de textos de segunda generación, los capítulos o subcapítulos sobre el tema en Historias de la Literatura.

He ordenado la bibliografía según un doble criterio, alfabético y cronológico, que creo el más funcional y económico de cara a la referencia a sus entradas. Cuando un artículo va seguido de la preposición en, debe entenderse que forma parte de un volumen colectivo.

Sólo me queda pedir disculpas por los errores y omisiones que, a pesar de todas las precauciones adoptadas, haya podido cometer.

\section{EDICIONES DE TEXTOS CLÁSICOS}

El hecho de que sólo podamos considerar clásicos, y por lo tanto regularmente presentes en las colecciones académicas de textos, el Fray Gerundio de Isla y la Vida de Torres es el mejor indicio de la tradicional desatención a nuestra novela del XVIII en la investigación y en la enseñanza; y no es tampoco muy feliz la circunstancia de que ambos "clásicos" sean dos intentos imperfectos y frustrados de novela.

La edición de Fray Gerundio por Sebold (1992 b) es reimpresión de la de 1960-1964, con la bibliografía al día. En su primera aparición, hace 30 años, el texto isliano, corregido por la edición príncipe para la primera parte y por el manuscrito autógrafo para la segunda, fue puesto por Sebold en manos de quienes para conocerlo tenían que acudir a la reimpresión en BAE y 1945 de la antigua edición de Monlau; y ese rescate añadía a su indudable valor y significación una anotación abundante y un sugerente e innovador estudio, en el que se trataba del carácter de Isla, su vena satírica, sus relaciones con la nobleza y los círculos literarios, Luis de Losada, Martín Martínez o Feijoo, y la consideración del Gerundio desde la oratoria barroca y la huella cervantina y picaresca, junto a su historia editorial y la de su polémica aparición, proceso y condena. La técnica de Isla recibía nueva luz al ser definida por Sebold como influida por el sensismo de Locke en cuanto a la descripción del medio ambiente y los personajes, y a la determinación de éstos por aquél. 
También en 1992 se publicó la monumental edición de Jurado (1992 a), destinada a investigadores y especialistas y llamada a sentar plaza de obligado y canónico instrumento de consulta y referencia.

Sitúa Jurado la significación del Gerundio en el marco de la génesis, cronología, características y degradación de la predicación del Barroco, y de las protestas contra la misma de escritores eclesiásticos y prelados desde los albores del XVII hasta Tavira, Climent y Lorenzana, sin olvidar a Mayans, Feijoo o Burriel. Señala, como anticipos de la obra editada, la juvenil Crisis de predicadores de Isla y los sermones que predicó desde 1735 .

Traza la historia de la circulación de Fray Gerundio en forma manuscrita y en busca de apoyo de cara a la publicación y a los previsibles ataques que estaba llamado a desencadenar; el éxito de venta de la primera edición y las delaciones y condenas de la obra; y un detallado y minucioso recuento de impresiones, identificando las numerosas fraudulentas.

Aportación muy destacable en esta edición, y síntoma de los conocimientos nada frecuentes que posee el autor en el ámbito de la historia de la literatura religiosa, es la afirmación, documentada y probada, de que Isla no inventó la mayoría de los sermones puestos en boca de Gerundio, sino que los tomó de textos reales publicados por los predicadores más célebres de la España del segundo tercio del siglo, lo que explica la inmediata y furibunda reacción de la mayoría de las órdenes religiosas, hecho que fue posteriormente utilizado en la maquinación que dio lugar a la expulsión de los jesuitas, como documenta el Dictamen fiscal de Campomanes.

Finalmente, conviene destacar que Jurado califica las pretensiones de Isla de más satíricas que novelescas, dado que en Fray Gerundio no hay personajes propiamente dichos ni argumento, sino engarce de episodios inconexos. No cabe olvidar, entre los méritos de esta edición, la publicación de todos los preliminares, y sus casi 4.700 notas.

La edición de Álvarez Barrientos (1991), en una colección de propósito fundamentalmente divulgador, tiene el acierto de afrontar, con la relativa extensión a su alcance, el problema de enfocar el Fray Gerundio ante todo como novela, recordando los juicios de Juan Andrés, Arteaga o Moratín, y situando el texto isliano en sus coordenadas satírica, novelesca y cervantina, y en el contexto de la novela europea de la época y de las reflexiones e intenciones de su creador.

En el estudio preliminar a su edición de la Vida de Torres (1985 a), más extenso de lo esperable en una colección de las características de la que la acoge, Sebold define como claves de la espiritualidad torresiana el conflicto entre mundaneidad y ascesis y humorismo. A la hora de valorar la actitud de Torres ante el dilema entre conservadurismo y progresismo, no duda en considerarlo un inmovilista, arcaico en su pensamiento científico y lleno de reservas ultramontanas, 
todo lo cual "revela del modo más palmario su postura antiilustrada, antimoderna, antifeijoniana y archicatólica". Tras señalar la ruptura del discurso narrativo que se produce en el desacertado Trozo $6^{\circ}$ de la Vida, Sebold la considera un ejercicio de oscilación entre el modelo de las autobiografías ficticias de pícaros y las biografías de santos, frailes y monjas, y se ocupa de su doble método de captación del yo (la introspección agustiniana y la inducción baconiana) y de su atención minuciosa al realismo de lo cotidiano.

Muy distinto es el enfoque de Pérez López (Torres 1989): su estudio preliminar, o égloga piscatoria, tiene tanto de trabajo académico como de apología alternativa a la interpretación de Sebold. El propósito del profesor salmantino es sacar del Purgatorio al "genial y maltratado Torres", rectificar su imagen de contrafigura reaccionaria de Feijoo, ver bajo nueva luz su personalidad y su entidad de científico y pensador, atravesando su reductora y deformante imagen de almanaquero.

Para Pérez López, el movimiento de los novatores (1680-1726) fue un reformismo prudente y solapado, cauteloso ante la amenaza inquisitorial y la falta de apoyo desde el poder, frecuentemente camuflado bajo protestas de ortodoxia. Sitúa en su seno a Torres, en quien llega a ver a un pre-ilustrado a propósito de la ciencia moderna y la crítica de la Universidad y la función social de la nobleza.

En cuanto a la Vida, se extiende el editor sobre su naturaleza y precedentes, sus referencias a la picaresca como "modelo subvertido", la singularidad y ambigüedad del "pacto autobiográfico" torresiano y la necesidad de superación por la crítica de la oposición radical entre autobiografía y novela. Los señuelos para repescar a Torres, como intelectual y como novelista, están pues sobre la mesa; acaso, si el piscator llega a ser pescado, podamos comprobar que no fue un espantoso saurio sino un grácil cisne sin lago.

La infantil y escolar selección de Aranda (Torres 1985 b) tuvo el propósito de conmemorar la creación del I.N.B. "Torres Villarroel" de Salamanca. Torrente Ballester, en su día profesor del centro, le antepuso una página que, sin pretender ser más que un espaldarazo afectuoso, se lee con el mismo placer que todo lo nacido o caído de su pluma.

\section{MISCELÁNEAS}

Madrid en la novela forma parte de una colección creada para documentar la presencia de la capital de España en la literatura. Tiene en cuenta textos narrativos de Fulgencio Afán de Ribera, Antonio Muñoz, Isla, Torres, Olavide, Eugenio de Tapia y otros. La introducción estudia la conversión de Madrid en espacio imaginario y su relación con la evolución histórica de la ciudad.

La antología de Torres (1994), no venal, vino a conmemorar la Fiesta del Libro del año de su publicación. Incluye capítulos escogidos de la obra en prosa del autor, desde el Correo del otro mundo a la Vida. 


\section{EDICIONES DE TEXTOS RECUPERADOS}

Es en este terreno donde se ha producido, en el último decenio, el más espectacular avance en cuanto a autores desconocidos y olvidados o a obras inaccesibles.

En 1985 aparece El Valdemaro: lo creo una de las mejores y más atractivas novelas de la época, razón por la cual lo situé el primero en mi calendario de investigaciones sobre la novela española del XVIII. El estudio preliminar pasa revista a las obras de Martínez Colomer (nacido en 1762), clasificándolas en histórico-políticas, poéticas y narrativas. En estas últimas, que pueden dividirse en relatos de costumbres contemporáneas, y fantásticos, exóticos y de aventuras, interesa la percepción emocional de la Naturaleza como fuente de introspección, el cultivo del sentimentalismo y el patetismo y el recurso a lo sobrenatural y onírico. El Valdemaro, entretejido de viajes, peligros, naufragios, desarreglos emocionales y suicidios, exige tener en cuenta a su autor, traductor del René de Chateaubriand, en todo balance del origen dieciochesco del Romanticismo español.

Dos años después nos ofreció Gérard Dufour la célebre Cornelia Bororquia (Gutiérrez 1987), legendaria por su tinte anticlerical, por la persecución inquisitorial de que fue objeto y por haber merecido la popularidad del pliego del cordel y haber inspirado a Blanco White su Vargas. La obra, siempre anónima, es atribuida convincentemente por Dufour a Luis Gutiérrez, fraile exclaustrado, redactor de la Gaceta de Bayona, a quien la Junta Central hizo ejecutar como agente francés en 1809. Identifica Dufour, como fuentes de la Cornelia, ante todo De la cruauté religieuse de D'Holbach, junto a la historia de la Inquisición de Limborch y los tratados sobre la tolerancia de Voltaire y Locke. No la tiene por novela gótica propiamente dicha, y en ello estoy de acuerdo, aunque puede figurar entre las obras con rasgos góticos a las que se alude en Carnero 1993.

La edición de 1994 aparece en una colección popular de poca exigencia, a pesar de lo cual resulta llamativo que ignore la de Dufour, publicada 7 años antes por el Instituto Juan Gil-Albert de Alicante, y que en nota 35 de pág. 31 se mencione la vaga noticia de que "una Universidad del Levante español, la de Alicante o Murcia, preparaba una edición de la Bororquia".

No es menos destacable la publicación, en el mismo año 1987, de las Obras selectas de Pablo de Olavide a cargo de Estuardo Núñez, un grueso volumen dedicado parcialmente a la producción narrativa del autor de El Evangelio en triunfo. Desgraciadamente, este y los anteriores volúmenes consagrados por Núñez a Olavide son inencontrables en librería y raros en bibliotecas.

En 1971 aparecieron simultáneamente tres libros firmados por Núñez, que son precedentes del de 1987: Obras narrativas desconocidas y Obras dramáticas desconocidas de Olavide, y la biografía El nuevo Olavide. Los dos primeros con el sello de la Biblioteca Nacional del Perú, el tercero a cargo al parecer del autor, e impreso en 1971 según el colofón aunque en cubierta indique el año 
anterior. Obras dramáticas desconocidas recogía 9 dramas, uno de ellos ( $E l$ celoso burlado) original y los demás traducciones de Racine, Voltaire, Du Belloy, Lemierre, Mercier, Regnard. Obras narrativas desconocidas daba cuenta del hallazgo, en la New York Public Library, Brown University, Harvard University y Philadelphia Free Library, de las ediciones neoyorquinas de 1828 de El Incógnito, Paulina, Sabina, Marcelo, Lucía y Laura, y las publicaba precedidas de un breve estudio que las ponía en relación con el vol. IV de $E l$ Evangelio en triunfo como garantía de su originalidad, y anunciaba la existencia de una séptima novela aún no localizada, El Estudiante.

Por su parte, El nuevo Olavide, salvo retoques y alguna adición, es la mera refundición de los prólogos de los dos volúmenes citados. Lo mismo puede decirse del estudio preliminar de la edición de 1987, con la salvedad de las páginas dedicadas al nuevo hallazgo de Núñez, Teresa o el terremoto de Lima, y aquellas otras que acusan recibo de la identificación de Olavide con el "Atanasio de Céspedes y Monroy" que figura como autor de las Lecturas útiles y entretenidas publicadas en Madrid entre 1800 y 1817, y de la de algunas de las supuestas novelas originales como adaptaciones (asunto al que me referiré en la segunda parte de este artículo). En 1987 se añade, a las 6 novelas publicadas en 1971, Teresa y dos fragmentos (La maldición paterna y Un cuento).

El interés y el valor de las publicaciones realizadas por Núñez es evidente y no necesita comentario. Cabe sin embargo preguntarse por qué nos deja la impresión de considerar con reticencia todo lo que no sea la trayectoria de sus propias aportaciones, remodeladas una y otra vez a lo largo de 30 años sin apertura al exterior, y por qué nos parece un investigador eterna y reiteradamente improvisado.

En 1989 vio la luz un texto (Isla 1989) no novelesco pero directamente relacionado con nuestro tema: la Apología por la Historia de Fray Gerundio, en edición preparada por José Jurado. Se trata de la respuesta de Isla a la delación del general de los carmelitas descalzos contra su novela, presentada en Febrero de 1758. La Apología, redactada en la segunda mitad de 1759, y publicada por primera vez sobre el manuscrito autógrafo, consta de 4 cartas que contienen la defensa del Gerundio, comentarios sobre teoría de la novela basados en Aristóteles, Luzán y Le Bossu, y sobre Virtud al uso de Afán de Ribera, censura del sermonario del delator, fr. Pablo de la Concepción, y referencia a algunos sermones auténticos que fueron base de la sátira isliana.

Mi edición de obras de Pedro Montengón (Montengón 1990) contiene dos novelas y una selección de Odas. En el extenso estudio preliminar trazo la trayectoria biográfica del autor y estudio todas sus obras, con especial detención, entre las no novelescas, en las poéticas. En cuanto a las novelas montengonianas, existiendo la reciente edición de Eusebio (1984) por Fernando García Lara, preferí Eudoxia y El Rodrigo, aparecidas ambas en 1793. La primera, por plantear la formación de la personalidad de la protagonista en lucha contra tribulaciones y adversidades derivadas de la desgracia de su padre 
Belisario, tratar de la educación de la mujer y ser un contrapunto, centrado en ésta, del Eusebio, en el ámbito de la novela pedagógica. La segunda, por estar libre del didactismo explícito, concebir la atormentada y vacilante personalidad del último godo como "byronic hero" y ser, como afirmó Menéndez Pelayo, la primera novela histórica del Romanticismo español.

Dos años después publiqué las dos novelas de Gaspar Zavala y Zamora (1992). Descubrí su partida de bautismo, según la cual nació en Aranda de Duero (y no en Denia, como afirman los repertorios desde 1830) en 1762. Dejando a un lado su obra dramática, estudié sus traducciones de Florian, $L a$ Eumenia y Oderay. En cuanto a la primera, pude tener acceso a la edición príncipe en la biblioteca de Russell Sebold, y destaqué los ingredientes sentimentales, los temas derivados de la mística del matrimonio, la visión emocional de la Naturaleza, el empleo del lenguaje de la pasión y el eco rousseauiniano.

La segunda es traducción de un anónimo Odérahi (1801) que se considera fuente de Atala, René y Los Natchez de Chateaubriand. La adaptación de Zavala tiene la relevancia de haber divulgado en la España de su tiempo el exotismo americanista, y un relato rezumante de pasión amorosa, con toques lúgubres y macabros y una decidida crítica de la religión institucional, de la teología dogmática y del sacerdocio, que Gaspar Zavala se creyó obligado a dulcificar.

Las dos últimas ediciones que debo citar se encuentran en prensa en el momento de redactarse estas páginas.

Según Joaquín Álvarez Barrientos, a quien debo las noticias sobre la suya de Francisco de Tójar (1995), los Cuentos morales son originales de SaintLambert, y La filosofía por amor de Gatrey. Queda pues arrumbada la poco convincente hipótesis de que la segunda fuera adaptación parcial o trasunto de La nouvelle Héloïse. El interés de ambas obras, afirma su editor -y estoy completamente de acuerdo, como demuestra mi atención a Oderay-no disminuye al tratarse de adaptaciones. Los Cuentos lo deben a su exotismo oriental. la novela a la filiación rousseauniana y a la dimensión contestataria de la protagonista. El estudio preliminar contiene también precisiones biográficas sobre Tójar, su modo de traducir y sus empresas editoriales.

Al editar la obra narrativa de Ignacio García Malo, mi primera ocupación ha sido construir su biografía. Gracias al expediente de concesión, en 1800, de la orden de Carlos III, he localizado su partida de bautismo en el Archivo Diocesano de Cuenca, y sabemos que nació en Castillo de Garci Muñoz en 1760. El Archivo de Secretaría de la Biblioteca Nacional de Madrid conserva su expediente de empleado de la Real Biblioteca entre 1789 y 1798 . Entre 1794 y 1806 fue secretario de la Real Capilla y del Vicariato General Castrense, y en 1809 oficial segundo (Quintana era el primero) de la secretaría de la Junta Central. Disuelta ésta en 1810, pasó García Malo a desempeñar la intendencia del ejército de Baleares hasta su muerte en 1812, tal como puede documentarse en el Archivo Histórico de Baleares. En el Diocesano de Palma he localizado su 
partida de defunción, y su expediente testamentario en el de Protocolos de la misma ciudad.

Sigue mi estudio preliminar tratando de la obra política de García Malo, de su relevancia como traductor (de Pamela de Richardson y de la Ilíada), de su teatro (la tragedia neoclásica Doña María Pacheco, la tragedia burguesa Guillermo de Hanau, una ópera) y de su producción novelística, la colección titulada Voz de la Naturaleza.

Consta ésta, en su estado último de 1803 ( $3^{\mathrm{a}}$ edición) de 12 novelas, de las que publico las 8 que me han parecido de mayor interés, dentro de un ámbito temático que incluye la libre elección de estado y cónyuge, la acertada o equivocada administración de la virtud femenina, la casuística moral y sentimental de la pasión amorosa y la excelencia de la beneficencia ilustrada. En cuanto a las fuentes de inspiración de García Malo, creo haber identificado como tales Pamela, Il re pastore de Metastasio, Contes moraux de Marmontel, Adela y Teodoro de Mme. de Genlis, El Evangelio en triunfo de Olavide, Émile de Rousseau y otras.

Aunque ello no concierna directamente a nuestro tema, debo aludir brevemente a un par de cuestiones antes de cerrar este apartado.

En el panorama editorial español brillan por su ausencia las traducciones de novela dieciochesca extranjera, que tanto ayudarían a situar la nuestra en su adecuado contexto. Aunque es cierto que los especialistas las leen en su lengua original, tenerlas en la nuestra las haría más accesibles y extendería su audiencia. Debemos pues felicitarnos por la publicación en 1985 de la traducción de Marchena de Las ruinas de Palmira de Volney (Madrid, El Museo Universal), en 1989 de una selección de El Almacén de los niños de Mme. Leprince de Beaumont (ed. Á. Olalla, Univ. de Granada), en 1990 de Manuscrito encontrado en Zaragoza de Potocki (Madrid, Palas Atenea, ed. F. Arbós sobre la de R. Radrizzani), aunque no siempre se trate de ediciones preparadas con los debidos criterios ni provistas del esperable aparato crítico.

Por otra parte, si bien es cierto que en el último decenio el progreso en la edición de novela dieciochesca española ha sido muy notable en relación al inmediato pasado, debemos reconocer que en España no existe un solo sello editorial, comercial, universitario o institucional, que preste atención sistemática a tales recuperaciones, de modo que cada una de ellas ha de ser laboriosamente gestionada, entre toda clase de precariedades. La comparación con la situación en Francia, sin ir más lejos, resulta desalentadora. La editorial Desjonquères (distribuida nada menos que por P.U.F.) ha publicado en 1985 Mémoires du comte de Comminge de Mme. de Tencin, en 1987 La poupée de Jean Galli de Bibiéna, en 1991 Pauliska de Jacques Révéroni Saint-Cyr; la Universidad de Saint-Etienne, en 1992 y 1993, Voyage merveilleux du prince Fan-Férédin de Guillaume $\mathrm{H}$. Bougeant, Le voyage à Brunswick de Adolph Freiherr, Imirce de Henri Dulaurens; la editorial ginebrina Droz, en 1991 Les 
illustres françaises de Robert Challe, en 1992 Lettres de Mylord Rivers de Mme. Riccoboni, en 1993 Continuation de l'histoire de Don Quichotte del mismo Challe. Al mismo tiempo, resulta prometedora la actividad de pequeñas editoriales artesanales como L'Horizon Chimérique de París o Ganymède de Bourges, que nos han ofrecido, respectivamente, L'Espion chinois de Ange Goudar (1990) y Zingha, reine d'Angola de Jean L. Castilhon (1993).

Es asimismo digna de imitación la iniciativa de la editorial neoyorquina A.M.S. Press al haber emprendido el llamado "Clarissa project" bajo la dirección de Florian Stuber, consistente en una serie de 16 vols. que incluyen el facsímil de la edición de 1751 ( 8 vols., aparecidos en 1990), materiales complementarios y variantes ( 3 vols.) y recopilación de la tradición crítica sobre la obra desde su publicación ( 5 vols.).

\section{ESTUDIOS}

\section{Generalidades}

Lo primero que debe destacarse es la gran utilidad que como instrumento de trabajo tiene la Bibliografía de Aguilar Piñal (1981-1993).

Sobre el tema de la falta de novela en la España del XVIII, Domergue 1985 arguye la hostilidad en términos morales, la persecución inquisitorial de obras impresas en el país (Gerundio, Eusebio) e importadas, la prohibición en censura previa de muchas que hubieron de quedar manuscritas, y la general de 1799. Su conclusión -es innecesario decir que no la comparto-es que no puede hablarse de despegue en los últimos decenios del siglo, debiendo para ello esperarse a la cuarta década del XIX. Rodríguez 1985 calcula en unos 250 títulos la producción española entre 1700 y 1833 , y la subdivide en tres apartados: supervivencia de la picaresca e imitación del Quijote, restrictivamente entendido como sátira; relatos morales y didácticos; introducción de la corriente sentimental sobre modelos ingleses y franceses. Poco después (1989) argumenta que las razones tradicionales para explicar el subdesarrollo novelístico español no son convincentes, habiendo aquéllas de ser buscadas en la predilección por la lectura en voz alta, hábito y rutina en ambientes cultos y necesidad en los iletrados. Así se explicaría la supuesta predilección por la novela corta y compendiada, y el hecho de que las formas innovadoras (con descripciones extensas, desarrollo lento y análisis psicológico en el ámbito de lo sentimental), al requerir lectura individual y solitaria, fueran mal recibidas.

Álvarez Barrientos 1990 destaca el desarrollo de la novela española y de las colecciones en el último tercio del siglo, y cómo el género pone en cuestión convenciones, ideología dominante y relaciones entre clases, bajo la mirada vigilante de la censura. Señala que la perspectiva moral adoptada por la novela no es siempre de estirpe religiosa, sino a menudo laica, centrada en los problemas de "condiciones" y "relaciones" -en la terminología de Diderot, y el valor costumbrista de muchos de nuestros relatos dieciochescos. 
En el monográfico de Ínsula (1992), Aguilar Piñal aporta una obertura en que aparecen la proliferación sentimental, la crisis de valores tradicionales, el auge de los personajes femeninos y la escasez de traducciones. Álvarez Barrientos discute el tópico del "vacío novelístico" del XVIII español, tal como se formula en Menéndez Pelayo y Mesonero, y la marginación de la novela en la preceptiva y en la historiografía dieciochescas, salvo en Juan Andrés. García Lara apunta, como temas de interés actual, los esfuerzos bibliográficos, la investigación sobre Torres y las utopías, y las perspectivas aportadas por Zavala 1987. Escobar, la continuidad del Costumbrismo entre los siglos XVIII y XIX, la relevancia de la prensa periódica y el conflicto entre la noción neoclásica de imitación y la observación de la realidad social.

$$
* \quad * \quad *
$$

En materias algo más específicas, pero que con todo caben en este apartado, debe destacarse en primer lugar el volumen publicado por Iris Zavala en 1987. Dejemos a la autora exponer sus propósitos (pp. 3-4):

Nuestro análisis se basa en métodos de la teoría de la recepción (no sin adaptaciones), métodos de análisis textual y algunas formulaciones de Batjín respecto a la narrativa y los enunciados, así como en aquellas re-formulaciones de la amplia gama de la semiótica que sitúan el fenómeno literario dentro del acto comunicativo $y$, por tanto, en la vida social.

Nuestros intereses de investigación y sus limitaciones quedan explícitos en los supuestos de los que parto:

1. Definir a los lectores (reales, ficticios, internos, concretos).

2. Definir el texto como tipo específico de enunciado.

3. Reconstruir, dentro de lo posible, el diálogo interrumpida de los textos narrativos como otros textos.

4. Indicar las fuerzas monológicas sociales que impidieron el intercambio.

Mi objetivo es mostrar que algunos de los tipos de géneros novelescos aparecidos en el sigio XVIII tuvieron escasa repercusión en España (y el mundo hispánico) y explicar las razones para que esto sucediera. En cuanto acto comunicativo (red de enunciados sociales), el texto es la realidad primaria y el punto de partida. Todo texto es un conjunto de prácticas textuales, un todo orgánico dentro de un proceso de producción dinámica que origina, a su vez, un proceso de recepción o práctica, en el interior del sistema de comunicación y de interacción (me apoyo en la definición de Van Dijk 1984: 2281). Desde este sistema semiótico se define la norma y la transgresión de la norma; la Inquisición, en cuanto receptor privilegiado, creó una ruptura en el sistema comunicativo, en el código, e impuso el discurso dominante, interceptando así a menudo el circuito comunicativo (al menos en la superficie).

Mucho de cuanto circuló hubo de adaptarse a la norma y a la convención, cuando no circular clandestinamente.

Parto de una propuesta general que intenta integrar discursos y receptores, con sus códigos y normas determinados de asociación y combinación. Tocamos así e] gran dilema entre fidelidad y libertad. Propongo que un análisis de las estrategias textuales permite verificar que el emisor intenta impedir una utilización indiscriminada de la obra, y sugiere los códiggos para la reconstrucción del mensaje. Las estrategias textuales ponen de relieve una decisión muy clara respecto al lector social concreto a quien se dirige el discurso. 
Considero como extremos en este circuito de lectores aquellas lecturas "privilegiadas" que delatan su presencia e imponen un significado institucional. Finalmente, examino tres discursos narrativos-Torres Villarroel, José F. de Isla, José Cadalsoen los cuales la función lectora, el acto de comunicación, se nos revela como eje central de la organización textual. En cierto modo, los tres se adaptan a modelos ideológicos externos (gusto, poéticas) y formulan distintamente el uso particular de la norma en la trama, el tema, la estructura. En cuanto comunicación semiótica se combinan en un nuevo estilo o en dependencia a una tradición. La re-actualización de los modelos del siglo XVII (en particular, Cervantes, Alemán y Quevedo), se inserta dentro de una tradición que no supone polémica con sus precedentes literarios. Torres Villarroel e Isla, en particular, se apoyan en la cultura de la risa; Cadalso, en cambio, supone otros diálogos intertextuales".

El libro resulta una amalgana de textos no siempre bien soldados y a veces reiterativos, servidos con salsa semiótica y guarnición bajtiniana. En el fondo, un hato de cosas sabidas, bajo una terminología sacramental a la que podría aplicarse el verso de Boileau: "La montagne en travail enfante une souris". Quienes conocemos a Iris desde antiguo y apreciamos su trayectoria investigadora no podemos menos que lamentar este experimento que nada le añade. Decía el Arcipreste de Hita que "non ha mala palabra si no es a mal tenida"; espero que Iris entienda las mías, porque las dicta el deber de no falsear lo que creo la verdad.

Bermúdez Cañete 1989 rastrea la influencia de Rousseau en diversos españoles del XVIII, entre ellos Montengón y Mor de Fuentes. Guinard 1990, desde la distinción entre utopía, viaje imaginario y novela, señala que, con todo, en nuestro fin de siglo aparecen novelas con episodios o ingredientes utópicos: así el Eusebio (mito de la Pennsylvania cuáquera), El Mirtilo, El Antenor (la república de Elime), El Valdemaro y las Aventuras de Juan Luis (La isla Fortunaria).

Truxa 1990 estudia algunas novelas sentimentales españolas (La Serafina, La filósofa por amor, La Eumenia, Rodrigo y Paulina), las distingue y caracteriza por su planteamiento del problema del amor y el matrimonio desigual: que el cónyuge impuesto aparezca después de la mutua declaración de amor entre los protagonistas, quedando privado de legitimidad; el debate entre rango y dinero frente a virtud; que el atractivo para ser amado no resida en la belleza física sino en la moral, por lo cual resulta infrecuente la descripción de la primera.

En Carnero 1993 se delinea la trayectoria semántica de la palabra "gótico" y sus cambios valorativos en el XVIII, desde el desprecio y la reprobación a la reivindicación en términos emocionales, en los ámbitos del medievalismo y la sublimidad. Se caracteriza en un esquema de nueve componentes el goticismo literario (época remota no imprescindible; lo terrorífico moral del tirano gótico, laico o eclesiástico; la debilidad de los héroes; los personajes marginados; la heroína atribulada; lo terrorífico natural; lo terrorífico arquitectónico; lo terrorífico religioso; lo terrorífico sobrenatural), se plantea su incompleta manifestación en la España del XVIII y se señalan elementos góticos en Eusebio y El Rodrigo, La Leandra, Cornelia Bororquia y la Galería de Pérez Zaragoza.

Álvarez Barrientos intenta, en 1995 a, determinar los rasgos diferenciales de la novela moderna, tomando como punto de partida las reflexiones del $P$. 
Isla y siguiendo con otros textos de preceptiva y de práctica novelesca. En 1995 b estudia la ambivalencia hacia lo francés en la España de fines de siglo, tomando en consideración el testimonio de varias novelas y la presencia francesa en la vida y la cultura del país. En 1995c plantea el incremento del número de mujeres lectoras y escritoras en la España del XVIII, aunque la mujer siga siendo marginada en la educación y sea objeto, en la narrativa de la época, de un tratamiento conservador centrado en realzar la virtud y la pasividad femenina ante el padre o el amado, mientras otras orientaciones progresistas (Prévost, Marivaux, Laclos) toman en cuenta la libertad en la elección de estado, e indagan la psicología y la iniciativa femeninas en materia amorosa.

La Eumenia de Zavala y Zamora, La Serafina de Mor de Fuentes y Maclovia y Federico nos sitúan, en el caso de la novela española, ante mujeres resueltas y combativas, si bien lo son en cuanto a sus esfuerzos para unirse al hombre que aman. Lo mismo ocurre en La filósofa por amor de Tójar, con la peculiaridad de que, en este caso, la protagonista, siendo de familia noble, rica y poderosa, no sólo reivindica su amor por un joven sino que toma la iniciativa amorosa.

Todo ello revela, según el autor, la inquietud de la época por plantear un nuevo modelo de relación entre hombre y mujer que adapta, humaniza y relaja el tradicional, más para apuntalarlo que para disolverlo.

Alonso Seoane 1995 b indaga la presencia de la novela en el teatro (relatos dramatizados, novela como tema dramático) y la del teatro en la novela (como tema y como actividad de los personajes, como acción relacionada con la novelesca, como excurso dramático incrustado en el texto de la novela).

Véase Tietz 1992, que no he podido consultar.

Sobre Cervantes y la novela aureosecular en el XVIII, véase Aguilar Piñal 1987 a y 1987 b (pp. 247-255); Álvarez Barrientos 1987-1988, 1989; Baquero Escudero 1988; Barrero Pérez 1986; Ertler 1989; Fernández Insuela 1993; Meregalli 1993; Pensado 1987; Ripoll \& Rodríguez de la Flor 1991; Rodríguez Cepeda 1988 a y b, 1992. También Fernández Insuela 1986 y Lopez 1988.

La ubicación de la novela en el contexto teórico del Neoclasicismo es un tema que viene interesando últimamente a los dieciochistas, entre otras razones por ser uno de los obstáculos posibles en la tardía adquisición por el género de carta de naturaleza. Se tiene en cuenta su ausencia en la preceptiva clásica, los intentos dieciochescos de definir la novela como variante en prosa de géneros canonizados (epopeya, tragedia, comedia...), la obsesiva coartada moralizante de cara a un público refractario a la literatura doctrinal y ansioso de entretenimiento y deleite emocional, la distinción entre novela y romance en función del carácter cotidiano-realista o maravilloso-exótico, o de la menor o mayor extensión del relato.

Una exposición sintética de estas cuestiones, en el resumen de Checa 1992. Álvarez Barrientos 1991 a recopila un siglo de ideas sobre la novela, en Gregorio Mayans (Vida de Cervantes, Retórica), José Luis Munárriz (traducción de las Lecciones de Hugh Blair), Francisco Sánchez Barbero (Principios 
de Retórica y Poética), Agustín García de Arrieta (traducción adicionada de los Principios filosóficos de la literatura de Charles Batteux), José Marchena (Lecciones de filosofía moral y elocuencia), José Gómez Hermosilla (Arte de hablar en prosa y en verso). El caso de Mayans (su consideración analógica de la novela en el marco de la poética clásica, su incapacidad para admitir su independencia y novedad, sus opiniones sobre Cervantes, las novelas picaresca y de caballerías) ha sido estudiado por Pérez Magallón (1986-1987, 19901991); véase también su edición de 1994, primer intento de poner al alcance del estudiante universitario un compendio de textos mayansianos. En un denso y erudito artículo, François Lopez 1988 indaga la ambigüedad e imprecisión del concepto de novela en la tradición preceptiva, rastrea la historia de la división de la literatura en épica, lírica y dramática, y clarifica el pensamiento de Mayans (prólogo a La picara Justina, Vida de Cervantes, Retórica) a propósito de sus ideas acerca de la novela, su perspectiva moral en relación con la de Vives, su visión y valoración de la novela medieval y de la Edad de Oro, para concluir señalando la distancia entre ese pensamiento y la vulgata neoclásica. Sánchez García (1987) estudia las ideas expuestas por Vicente Mª Santibáñez en su prólogo a la traducción (1787) de La buena madre de Marmontel.

Fernández Insuela (1995 b, c) se ocupa de la vigencia del cuento tradicional en el XVIII, en la Tertulia de la Aldea, la literatura de cordel y un manuscrito titulado Diversión nocturna, de autor no identificado, existente en la Biblioteca Central de la Universidad de Oviedo.

En cuanto a las síntesis historiográficas y críticas sobre la novela española del XVIII, en mi opinión es prematuro planteárselas hoy por hoy si se pretende que tengan el debido rigor. La razón es que no disponemos todavía del suficiente número de monografías (y pasará algún tiempo antes de que podamos contar con ellas), y falta así la base sobre la que asentar aquéllas. Quien pretenda escribir hoy en día una historia de la novela española del siglo XVIII deberá asumirla como la tarea de toda una vida, so pena de heredar errores y lagunas, hablar en muchos casos por boca de ganso o arriesgarse al peligroso juego de tomar la parte por el todo.

Dos de tales síntesis se han publicado en el decenio que nos ocupa. La de Ferreras 1987 muestra el apresuramiento, el descuido, la vacilación de criterios y la falta de referencias de primera mano que son en el autor habituales, sin olvidar por ello la utilidad y el mérito de sus trabajos. La mejor, como mucho, es la de Álvarez Barrientos 1991 b, gracias a la cual cabe, por primera vez, recomendar un manual de consulta a los estudiantes universitarios, quienes hasta ahora no podían recurrir ni siquiera a las Historias de la Literatura, en las que se cubría el expediente gracias a Isla, Torres y algún otro autor testimonial como Montengón.

\section{Traducción, adaptación y recepción de la novela europea}

Me ocuparé primero de las publicaciones que tratan el tema desde un punto de vista general, y en segundo lugar de las que conciernen a la actividad de traductores concretos, o a obras específicas. 
Urzainqui 1986 afirma que las obras inglesas fueron habitualmente conocidas en sus versiones al francés, y que las traducciones españolas sólo aparecen en las dos últimas décadas del siglo, siendo preferentemente libros de viajes y novelas sentimentales. Rastrea acto seguido la prensa española en busca de anuncios y reseñas de traducciones (casi siempre aparecidos en Gaceta de Madrid, Diario de Madrid y Memorial literario), y compila los referidos a Henry y Sarah Fielding, Elizabeth Helme, Samuel Johnson, Sophia Lee, André M. de Ramsay, Samuel Richardons, Frances Sheridan y Jonathan Swift, advirtiendo de la circulación de obras anónimas, no identificadas o incluidas en colecciones. En su artículo de 1991 matiza el campo semántico de raducción en el siglo XVIII, dividiéndolo en 12 categorías: restitución (de una obra supuestamente "robada" por un extranjero, como el Gil Blas), compilación en misceláneas, abreviación o sinopsis (el sistema de la Bibliothèque Universelle des Romans), acumulación (adición e interpolación del original, frecuente en obras científicas, historiográficas y preceptivas), corrección según criterios morales o para obviar errores, nacionalización (adaptación a las costumbres, geografía u onomástica del país), generalización (el proceso inverso al anterior), actualización al tiempo presente de una obra antigua, recreación (adaptación o traducción libre), traducción propiamente dicha, parafrasis y continuación.

Lafarga 1988 enfoca a Luzán y al duque de Almodóvar como difusores en España de la cultura francesa. Observa en el primero la reprobación de la novela y su ignorancia de los grandes autores franceses e ingleses contemporáneos (Memorias literarias de París, 1751); en el segundo, un criterio moral menos rígido y un conocimiento detallado de la novela francesa de la época (Década epistolar sobre el estado de las letras en Francia, 1781). Un más extenso análisis de la citada actitud de Luzán se encuentra en Carnero 1990, donde se amplía lo apuntado en una publicación de 1984: la obsesión didáctica y regeneracionista de Luzán, su identificación de la cultura con las instituciones dirigidas desde el poder, su falta de atención a la literatura favorecida por la demanda espontánea, la superficialidad de su información en materias científicas, su conservadurismo timorato ante la filosofía y la literatura, su atención privilegiada al teatro y su condena destemplada de la novela contemporánea. Debo señalar que ese artículo de 1990 está desfigurado por numerosas erratas.

Según Aragón Fernández 1989 los grandes autores franceses del XVIII brillan por su ausencia en el ámbito de la traducción, o están representados por obras menores o dadas como anónimas, mientras predomina la recepción de la literatura religiosa. En el repaso que aporta conciernen a la novela los nombres de Fénelon, Baculard, Mme. Leprince de Beaumont, Mme. de Genlis, Florian, Prévost, Saint Pierre, Lesage, Laclos y Ducray-Duminil. Sorprendentemente, no se nos dan los datos bibliográficos, ni siquiera el año, de las traducciones.

Alonso Seoane 1990 considera los anuncios de novelas francesas e inglesas que aparecieron en el Correo literario de la Europa. Lopez (ibid.) tiene en cuenta toda clase de obras, y además de la publicación mencionada en el título, 
la Biblioteca periódica anual del Memorial literario; su conclusión es que, salvo el Gil Blas traducido por Isla, ninguna de las obras maestras de la novela francesa se difunde en España, por causa de la censura, aunque no debemos olvidar la lectura clandestina de las ediciones originales. Fernández Gómez \& Nieto Fernández (1991), para los años entre 1750 y 1808 , dividen las obras objeto de su estudio en 14 grupos; la novela es en su esquema un subapartado del apartado $1^{\circ}$ del grupo 13 (Literatura), y resultan mencionadas traducciones de Lesage, Marmontel, Florian, Leprince de Beaumont, Ducray-Duminil, Fénelon y Chateaubriand.

Debo advertir que, en ocasiones, los trabajos a los que acabo de aludir y a los que aludiré en el resto de este apartado no se refieren sólo al ámbito de la novela, aunque mi resumen recoja únicamente lo que la concierne.

La actividad de determinados traductores y adaptadores de novela extranjera en la España del XVIII ha sido asimismo objeto de estudios monográficos, de los que paso acto seguido a dar cuenta.

Bernardo M de CALZADA en Freire 1989, donde se ofrece un resumen biográfico y una recapitulación de sus obras, entre ellas versiones de Adela y Teodoro de Mme. de Genlis (1785), El viajador sensible de François Vernes (1791), el Antenor de Étienne Lantier (1802), Herman de Unna de ChristianneBenédicte Naubert (1807) y Don Quijote con faldas de Charlotte Lenox (1808).

José de COVARRUBIAS, su traducción del Telémaco (1798) y sus ideas sobre la naturaleza y calidad de la traducción son el objeto del artículo de Aragón Fernández 1991.

Sobre la Pamela de Ignacio GARCÍA MALO puede verse mi artículo de 1995 d, y mi estudio preliminar a García Malo 1995. El de MARTínEZ COLOMER 1985, para el René de este autor.

Pageard 1993 se ocupa de la deficiente versión de Werther realizada por MOR de FUENTES y publicada por Bergnes de las Casas en 1835, señalando que Mor ignoraba el alemán hasta el punto de ser incapaz de comprender el original en muchos momentos, lo cual no es, en este caso, su único defecto, pues abusó de los diminutivos hasta la cursilería, degradó el texto goethiano dándole un tono humorístico y salpicándolo de vulgarismos, cuando no convirtió la lengua directa del original en ampulosidad retórica y atenuó o suprimió lo que podría causar problemas en el terreno religioso.

Andioc 1991 nos sitúa en la Valencia de 1812-1813, donde Leandro MORATíN se encargó, junto a Pedro Estala, de la dirección del Diario de Valencia. Junto a los artículos que en dicho periódico le atribuyera Rafael Ferreres, René Andioc se centra en una Anécdota publicada en el número de 29 de Junio de 1813, en realidad traducción de Les deux consolés de Voltaire, la asigna a Moratín estudiando su lenguaje y la publica en compañía de su original.

Alonso Seonae (1988 a, 1988 b) identifica la fuente de tres de los relatos que componen el Decamerón español de Vicente RODRÍGUEZ DE ARELLANO: 
El sepulcro en el monte, La heroína francesa y La pérfida, o Enriqueta y Lucía, la cual resulta ser, respectivamente, Félix et Pauline de Pierre Blanchard, y Clémence d'Entragues y Henriette et Luci del Décaméron françois de L. d'Ussieux. También estudia, en los dos primeros casos, la versión española en relación con su original.

Sigue sus pasos García Garrosa (1991 y 1992 a) en cuanto a las Tertulias de invierno en Chinchón de Antonio VALLADARES de SOTOMAYOR; de las siete novelas que forman esta colección, La mujer singular resulta ser adaptación de La femme comme il y en a peu de Cuentos morales de Marmontel; Clemencia de Entragues, de Clémence d'Entragues, traducida como hemos dicho por Rodríguez de Arellano como La heroína francesa; Los príncipes de Armenia, o el grito de la naturaleza, de Les princes d'Arménie del mismo Décaméron françois. Estudia igualmente la autora las características de la adaptación realizada por Valladares a la vista de los correspondientes textos franceses.

Sobre Francisco de TÓJAR, véase estudio preliminar a Tójar 1995.

Para las versiones por Gaspar ZAVALA y ZAMORA de Odérahi y de las novelas de Florian, mi estudio preliminar a la edición 1992 del autor. En un artículo reciente (Carnero $1995 \mathrm{~g}$ ) he identificado la remodelación, por Zavala, de Anne Bell, histoire anglaise, de Épreuves du sentiment de Baculard d'Arnaud, en su tragedia burguesa Las víctimas del amor, estrenada en 1788: un buen ejemplo de cómo las versiones de textos extranjeros se realizan en ocasiones sin respetar las fronteras de los géneros literarios, y de cómo han de ser igualmente rastreadas.

En 1992 b, García Garrosa plantea la repercusión en España de la trilogía formada por las Mémoires du Comte de Comminge, novela de Mme. de Tencin (1735), Les amants malheureux, drama de Baculard (1764) y la Lettre du. Comte de Comminge à sa mère, poema de Claude Dorat (1764 también): Los amantes desgraciados de Manuel Bellosartes, Los amores del Conde de Cominges de Luciano Francisco Comella, el anónimo Cominge perseguido, el inédito Los amantes desgraciados de José Pablo Muñoz, todo esto en el ámbito del drama; la traducción anónima de la novela, París 1828 , reeditada en 1836 y 1837 junto al drama de Bellosartes y el poema de Dorat, bajo el título de Historia del Conde de Comminge.

Reservo el último lugar en este apartado para Pablo de OLAVIDE, porque su caso merece exposición más reposada y porque, a la vista de la investigación en marcha que lo concierne, debemos provisionalmente considerarlo en parte un adaptador y en parte un novelista original, aunque es probable que el paso de los años y a la aparición de nuevos trabajos nos lo deje en lo primero.

$\mathrm{M}^{\mathrm{a}}$ José Alonso Seoane viene dedicando a Olavide una serie de sucesivos artículos $(1984,1985$ a y b, 1986, 1988 d, 1989, 1991, 1992, 1993, 1995 a) que en conjunto, y no obstante algunas innecesarias reiteraciones, han de conside- 
rarse de capital importancia en sí mismos y como complemento y corrección del enfoque dado por Estuardo Núñez a la labor novelística de Olavide.

Intentaré resumir las aportaciones de Alonso Seoane del modo más sintético posible.

Olavide se interesa primordialmente por el teatro hasta la crisis de conciencia que le produce su condena inquisitorial. A partir de ese momento emprende una serie de obras de carácter reflexivo moral y religioso, la más conocida de las cuales es El Evangelio en triunfo. A esta época corresponden sus novelas, sobre las que contamos con referencias debidas a Fernández de los Ríos, Defourneaux, Capel y Ferreras, más las publicaciones de Estuardo Núñez.

Dichas referencias coinciden con la colección titulada Lecturas útiles y entretenidas, publicada en Madrid entre 1800 y 1817, en 11 vols. y a nombre de "Atanasio de Céspedes y Monroy", seudónimo que encubre la autoría de Olavide. Algunas de dichas novelas se reeditaron en Filadelfia, 1811, y New York, 1828. Su pensamiento resulta coincidente con el de El Evangelio en triunfo; sus temas principales son la formación del carácter virtuoso por la educación y la religión, el dilema campo/ciudad desde el punto de vista de la virtud y el vicio, la libre elección de cónyuge, la mala educación de la nobleza, la religiosidad ilustrada.

Su originalidad debe ser puesta en tela de juicio, y debe investigarse su dependencia de originales franceses. Sin dar por concluida dicha búsqueda, puede señalarse la fuente de tres de dichas novelas: Marcelo o los peligros de la Corte procede de Germeuil de Baculard d'Arnaud; Paulina o el amor desinteresado, de Ernestine de Mme. Riccoboni; El incógnito o el fruto de la ambición, de Félix et Pauline de Pierre Blanchard, que, como antes hemos visto, fue igualmente traducida por Rodríguez de Arellano con el título de $E l$ sepulcro en el monte. La escasez de referencias en la obra novelística de Olavide a la cultura y la geografía francesas no debe ser considerada un indiscutible síntoma de originalidad, ya que una traducción "naturalizada" (y tal es el criterio expresado en el prólogo a las Lecturas) habría eliminado aquéllas sustituyéndolas por sus equivalentes españoles.

En el apartado tercero de este balance, el dedicado a las Ediciones de textos recuperados, se ha dado cuenta de la aparición en 1987 de la edición de Obras selectas a cargo de Núñez y del contenido de su estudio preliminar. Núñez 1988 da noticia de la identificación de otra novela de Olavide, Teresa o el terremoto de Lima (incluida en la citada edición del año anterior), con su sinopsis argumental y las razones que apoyan la atribución.

Véanse también Gómez Navarro 1986-1987, Pajares 1992, Fernández y González 1990. 


\section{Novelistas originales españoles}

\section{- Ignacio GARCÍA MALO}

A mi artículo de 1995 d ya he aludido en el apartado Traducción, adaptación y recepción de la novela europea. Los restantes (Carnero 1995 b, c, e, f) están sustancialmente recogidos en el estudio preliminar a mi edición (García Malo 1995), de modo que remito al lector al apartado Ediciones de textos recuperados, añadiendo tan sólo algunas cuestiones que tienen aquí mejor lugar.

En 1995 e me ocupo de la obra política del autor de Voz de la Naturaleza. Consta aquélla de una Memoria manuscrita y de cuatro impresos, aparecidos entre 1810 y 1811 . La Memoria, compuesta en 1809, siendo García Malo funcionario de la Junta Central, reflexiona política y militarmente sobre la mejor prosecución y coordinación de la resistencia antifrancesa y sobre el peligro de emancipación, con ayuda inglesa, de las colonia americanas.

Los impresos (Reflexiones sobre los puntos más importantes en que deben ocuparse las Cortes, Los derechos de la soberanía nacional, Respuesta a la carta del ciudadano militar, La política natural) pretenden ofrecer a los españoles, faltos de educación política para el ejercicio de derechos y deberes en un estado democrático, compendios de pensamiento liberal: publicidad de los debates de las Cortes y libertad de imprenta, pacto social y soberanía nacional, capacidad de la nación para prescindir del sistema monárquico o de la dinastía borbónica, devolución de la corona a Fernando VII como monarquía constitucional, limitación de la autoridad del rey por su lealtad a la nación, la división de poderes y las leyes fundamentales.

A la vista de todo ello, expongo en $1995 \mathrm{f}$ mis razones para creer equivocada la atribución a García Malo por Aguilar Piñal (1981-1993, vol. IV, pág. 136) de una obra anónima, traducida del francés con el título de La voz de la naturaleza sobre el origen de los gobiernos, cuya primera edición se imprimió en 1813. Me baso en lo siguiente: 1ํㅡㄹ el nombre de García Malo no aparece en dicha obra; $2^{\circ}$, Aguilar Piñal la confunde con la colección de novelas Voz de la Naturaleza, ya que las signaturas que da corresponden a esta última, en todos los casos menos uno; $3^{\circ}$, el pensamiento político de García Malo, según lo expuesto en 1995 e, es incompatible con el que sustenta la obra atribuida, escrita originalmente por Jean-Baptiste Thorel: negación del pacto social y la soberanía popular como teorías revolucionarias y regicidas, afirmación del derecho divino y la autoridad absoluta de los reyes, extremismo antirrevolucionario, antidemocrático y antiliberal. Ni está demostrado, ni puede suponerse verosímilmente, que García Malo fuera el traductor de Thorel.

Alonso Seoane 1988 propone la influencia en una de las novelas de García Malo, Federico y Beatriz, episodio del naufragio y vida en la isla desierta, de los Comentarios reales del Inca Garcilaso. No lo creo así, porque los dos relatos no tienen la suficiente semejanza y porque, aunque la tuvieran, habría que demostrar la necesidad de su relación en el ámbito de uno de los tópicos 
más generalizados en la literatura de la época. Mi opinión sobre las fuentes o los modelos de García Malo puede verse en mi artículo de 1995 c.

\section{- Luis GUTIÉRREZ}

Sobre este personaje y su Cornelia Bororquia, véase Dufour 1987, en esencia idéntico al estudio preliminar, del que en su lugar me he ocupado, de Gutiérrez 1987. En Dufour 1993, poco más que la escueta mención de la novela en su contexto. Utrutia 1990 analiza y comenta su ideología. También téngase en cuenta Román Gutiérrez 1988, pp. 116-118, y estudio preliminar a Gutiérrez 1994.

\section{- Fernando GUTIÉRREZ de VEGAS}

Álvarez Barrientos 1993 comenta el contenido de Los enredos de un lugar, y justifica el atractivo histórico y costumbrista de la obra por su sátira de jueces y abogados (emparentable con la de Fray Gerundio), su descripción del caciquismo y las formas de conducta en un cerrado microcosmos social, y la proyección sobre ese ámbito de los propósitos reformistas de la llustración. La modernidad que descubre en la novela la cree debida a su atención al análisis psicológico de los personajes, al propósito realista en el reflejo de los ambientes y a la conciencia creativa del autor en cuanto a los fueros del género.

\section{- José Francisco de ISLA}

En un inteligente y sugestivo estudio, Briesemeister 1986 a nos invita a reparar en el juego de Isla con distintas dimensiones de la gestación y la recepción textuales: Gerundio como lector inhábil de textos sagrados y como pretexto para las alusiones del autor a sus lecturas parodiadas de textos contemporáneos; la parábola de la lectura erudita, de la crítica textual y de la ecdótica en lo relativo al supuesto manuscrito original, su traducción falsificada y el descubrimiento de dicha falsificación por el orientalista oxoniense; la perversión de la bibliografía por el dómine Zancas Largas; el esperpento de lectura y escritura colectiva en la confección del sermón fúnebre por fray Blas y Gerundio.

Martínez de la Escalera 1986 documenta la presencia de Feijoo en el horizonte intelectual y vital de Isla tras el impacto causado por la aparición del Teatro crítico, a través de las cartas escritas por éste a aquél y a otros, de las alusiones al primero en la obra del segundo y de sus intentos de conseguir la protección del ilustre benedictino para Fray Gerundio.

José Jurado ha dedicado a Isla en este decenio trabajos que revelan su minuciosa erudición y que han afluido al estudio preliminar de la edición de 1992. El de 1985 expone cómo la prohibición en 1758 del tomo II de Fray Gerundio, y de la reimpresión del I, desató la confección de ediciones clandes- 
tinas y piratas, que se enumeran, se describen prolijamente y se identifican como tales tras el análisis del papel, las viñetas y las erratas. El de 1989 estudia la evolución del sermón del Siglo de Oro y su progresiva adquisición, aun manteniendo las constantes estructurales tradicionales, de un tinte profano en temas, contenidos y recursos literarios, y de un primordial carácter de juego de ingenio en busca de la sorpresa, la brillantez y el aplauso. Culminando esa degradación en el período 1680-1750, la crítica de Isla coincide con la de Feijoo, Mayans, Luzán y numerosos escritores religiosos y prelados. Afirma Jurado que los sermones gerundiacos no son invención de Isla, sino que están tomados de autores conocidos, y algunos de ellos encumbrados, primordialmente del segundo cuarto del siglo; e identifica un centenar de tales referencias en Andrés Berlanga, José Gay, José López de Cotilla, Francisco Isidoro Andrés, Gabriel de Cintruénigo, Pablo Fidel de Burgos, Francisco Soto Marne y otros, dándonos así la clave de la enorme capacidad de escándalo de la obra de Isla, de su clamoroso éxito y de la fulminante reacción de las órdenes religiosas que condujo a la prohibición instantánea.

Recuérdese lo dicho en su lugar a cuento de la edición por el mismo Jurado de Isla (1989), sin olvidar los estudios preliminares a Isla 1991, 1992 a y b. Véanse asimismo Chen 1990, Precedo 1988, Rodríguez Pazos 1985. No he podido consultar Briesemeister 1986 b ni Zavala 1992.

\section{- Vicente MARTÍNEZ COLOMER}

Me remito a la edición, ya citada, de El Valdemaro (Martínez Colomer 1985 ) y a su estudio preliminar, del que Carnero 1985 es un resumen dedicado a la presentación del autor en los aspectos que lo hacen relevante en el contexto literario del fin de siglo. Cruz Casado 1988 dice haber hallado el manuscrito de la novela Los trabajos de Narciso y Filomela, que yo no conseguí localizar; tampoco lo localiza, aunque lo describe y publica algunos fragmentos. Esperemos que la novela completa vea pronto la luz.

Veáse Truxa 1995.

\section{- Pedro MONTENGón}

Fabbri 1985 analiza los ingredientes utópicos presentes en tres novelas de Montengón: El Antenor, El Mirtilo y Eusebio. En la primera, el episodio de la república de Elime y sus afinidades con Tomás Moro, el Telémaco y Sinapia; en la segunda, los esbozos de crítica social y la evasión de la realidad con refugio en la aldea idealizada; en la tercera, el mito de América como solar de tolerancia. En cuanto al viajero y literato sueco Lorenzo Ignacio Thjulén, me produce la misma sensación que un pelo en la sopa, con todo el respeto que me merece mi admirado amigo Maurizio Fabbri.

Pilar Palomo 1986 apunta la influencia de El Criticón en Eusebio a propósito de los dos elementos básicos de la novela pedagógica: el personaje 
dual, o sea la pareja formada por protagonista y preceptor, y el viaje como símbolo del aprendizaje que supone toda vida humana. Señala coincidencias estructurales y textuales entre las dos obras citadas, y la huella de los Comentarios reales del Inca Garcilaso en El Antenor a través de Los Incas de Marmontel.

El Mirtilo, la novela pastoril de Montengón, es el tema de Hafter 1991: las razones del protagonista para huir del mundo, la situación de la obra en la tradición bucólica, las ideas literarias que revela, la peregrinación alegórica de Mirtilo y su conclusión en el refugio del amor y la pureza. Sebold 1992, publicado previamente en $\mathrm{ABC}$ del año anterior, es una apretada síntesis divulgativa acerca de la relevancia de El Rodrigo (señalada por Menéndez Pelayo) como primera novela histórica del Romanticismo español, el significado de su subtítulo (romance épico), sus ingredientes fantásticos y el personaje de Florinda.

En lo que toca a mis propias aportaciones, debo recordar el estudio preliminar a mi edición de 1990 y la recopilación de 1991, que incluye textos de Gumersindo Laverde, Ángel González Palencia, Emilio Alarcos Llorach, Elena Catena, Fabbri, Piero Menarini, Annick Emieux y Pilar Palomo. En mi artículo de 1995 a he inventariado las apariciones de la figura legendaria del rey Rodrigo en la obra de Montengón (Odas, la novela de 1793, el poema de 1820 La pérdida de España reparada por el rey Pelayo), para luego analizar los rasgos psíquicos de que Montengón lo dota (vacilación entre la equidad y la razón de Estado, el rendimiento amoroso y la violencia erótica, el orgullo y el arrepentimiento, la crueldad y la inclinación al suicidio) convirtiéndolo en un ser desesperado que sin descanso teje y desteje contradicciones jamás resueltas, víctima de un destino ominoso que le veda la satisfacción, la convicción y la fortaleza y lo conduce a la ruina moral y a la muerte, haciendo de él un personaje del ámbito del byronic hero romántico y guarnecido de cultura clásica, síntesis nada infrecuente en las manifestaciones dieciochescas del Romanticismo.

Véanse también Emieux 1985 y 1988, Fabbri 1992, Giménez López 1993, Gómez Navarro 1986-1987, Pajares 1991, Pérez Rioja 1988.

\section{- José MOR de FUENTES}

Hafter 1986 valora La Serafina por su carácter realista y por la singularidad que gracias a él adquiere en el contexto de su género y época, orientados hacia derroteros bien distintos. Tal realismo se detecta en el trazado del personaje de Alfonso tanto como en la no idealización amorosa de Serafina; en la conciencia, en las cartas que forman la novela, de la necesidad de controlar el énfasis sentimental; en las referencias críticas a la literatura entonces vigente en España; en la precaución acerca de la tendencia a interpretar las situaciones de la vida real en clave de tópicos literarios; en la descripción de tertulias, ambientes caseros, lugares de encuentro y tabernas; y en el uso, cuando procede, de lenguaje coloquial e incluso vulgar. 
Ruggeri Marchetti 1986 se propone, en un apretado volumen, llegar al planteamiento de todos los posibles niveles de lectura crítica de La Serafina: referencias temporales y al espacio físico en que la acción transcurre; estructura y ritmo del relato; clasificación, caracterización y función de los personajes, con especial consideración de los femeninos; tratamiento del omnipresente tema de la libre elección de cónyuge; condición social y educación de la mujer; crítica de la literatura contemporánea. Veáse Truxa 1995.

No menciono los trabajos dedicados al Bosquejillo por las razones indicadas en la Advertencia preliminar.

\section{- Francisco de PÁRRAGa MARTEL}

No podemos poner en el haber de este olvidado novelista otra cosa que el breve recuerdo de Cruz Casado 1992.

\section{- Diego Ventura REJÓN y LUCAS}

Unas páginas (11 a 21) de Peña Velasco 1985 desentrañan la confusión entre Diego Antonio Rejón de Silva y Diego Ventura Rejón y Lucas, supuesto seudónimo éste de aquél cuando se trata en realidad de dos personas distintas: Diego Ventura Rejón de Silva y Lucas, nacido en 1721 y autor de la novela Aventuras de Juan Luis, y Diego Antonio Rejón de Silva y Barciela, hijo del anterior y autor del poema La Pintura. Con documentos de primera mano nos ofrece la autora la biografía del novelista: su nacimiento en Murcia, su muerte en Madrid y otros pormenores y el catálogo de sus escritos, manuscritos e impresos, entre estos últimos la tragedia La Gabriela.

Soubeyroux ha dedicado dos artículos (1988 y 1991) a Aventuras de Juan Luis, entendida como una novela didáctica, satírica y utópica. Analiza el hispanista francés la ficción autobiográfica, la entidad del narrador, la estructura del relato (tópico del viaje, novels-within-the-novel) y el contraste que en él se establece entre Nogalia, el país donde vive el protagonista, aparentemente imaginario pero trasparente imagen de España, y la isla Fortunaria, en la que es abandonado tras ser apresado durante un viaje marítimo. Nogalia da ocasión a una sátira de la vida madrileña (vicios y defectos de hombres y mujeres, petimetría, terturlias y saraos), en contraste con una Fortunaria poblada de ciudadanos ilustrados y prudentes, y dotada de una organización social que se basa en la represión del lujo, de la ebriedad, de la mendicidad y del vagabundeo, la administración eficaz y rápida de justicia y la asistencia social a través de enseñanza y formación profesional de pobres y marginados. Observa Soubeyrous que, con todo, el programa reformista de Rejón es timorato y superficial, se basa en el autoritarismo y la represión y no cuestiona las estructuras sociales de la España del Antiguo Régimen. 


\section{- Alonso RIBERO y LARREA}

El autor del Quijote de la Cantabria ha merecido dos estudios de Fernández Insuela (1986, 1995 a), donde se ofrece el esbozo de su biografía y el repertorio de sus gustos teatrales neoclásicos y de sus ideas ilustradas: censura de la ociosidad e improductividad de la nobleza; condena de la ignorancia de los clérigos, de la superstición y de la explotación de la credulidad popular; regeneracionismo basado en el fomento de agricultura e industria, en línea de las Sociedades de Amigos del País.

\section{- TERTULIA DE LA ALDEA}

Esta miscelánea de autor y/o editor incierto, atribuida tanto a Hilario Santos Alonso como a Manuel José Martín, que se funda en la ficción de un grupo de personas reunidas para contar historias e incluye un variopinto conjunto de novelas del Siglo de Oro en compendio, vidas de santos, chistes y anécdotas folklóricas, tiene, según Fernández Insuela (1990 a, 1995 c) el interés de documentar la difusión conjunta de materia tradicional y literatura culta vulgarizada entre el público rural que hemos de suponer era su destinatario.

\section{- Diego de TORRES VILLARROEL}

Ilie 1986 se pregunta por la modernidad o el arcaísmo de Torres en relación a los "errores comunes", supersticiones y nociones precientíficas en un contexto español intelectualmente limitado y retrasado con respecto a Europa, e indaga sus ideas fisiológicas y epistemológicas y sus conceptos de imaginación y fantasía, en un sugestivo estudio cuyo alcance no se limita a la Vida de Torres, a la que sí debe limitarse esta exposición.

Para Picard 1988, locura y razón explican el carácter complejo y contradictorio de la imagen que de sí mismo quiso dejarnos Torres, más como configuración mítica de su personalidad que como testimonio confesional, finalmente decantada hacia la razón tras una brega de por vida en que la voluntad y la querencia moral logran el equilibrio último y buscan captar la benevolencia del lector.

Mercadier 1988 supone que el éxito de la Vida fomentó la publicación de autobiografías al filo del medio siglo, y señala dos de ellas (Vida y sucesos del astrólogo D. Gómez Arias, Vida y aventuras militares del filomatemático D. Joaquín de la Ripa), destacando el interés humano, literario y sociológico de la segunda, sus semejanzas y diferencias con el modelo torresiano y su sorprendente complacencia en lo truculento al relatar la expedición a Orán de 1732. Entre las autobiografías del XVIII enumeradas por Hafter 1993 en función de los elementos de crítica social que contienen, figura la Vida de Torres.

En Pérez López 1995 continúa la esperable revisión de la actitud de Torres ante la ciencia, las formas literarias del XVII y la ortodoxia religiosa, 
entendida en última instancia como una incompleta y frustrada aspiración a la modernidad.

Recuérdese el estudio preliminar del mismo Pérez López a Torres 1989, y el de Sebold a Torres 1985 a. Véase también Philippot 1986; no me ha sido posible localizar Delgado Gómez 1986 ni Gumbrecht del mismo año. Véase Fernández Cifuentes 1994 para la presencia de Torres en las Historias de la Literatura.

\section{- Joaquín TRAGGIA}

Para su actividad literaria, Arija Navarro 1987 desde pág. 321; unas líneas, en pág. 378, conciernen a la inconclusa novela pedagógica Eudamonopeia, considerada más detenidamente por Emieux 1991, que anuncia la futura publicación del manuscrito conservado en la Real Academia de la Historia de Madrid.

\section{- Cándido María TRIGUEROS}

A la miscelánea Mis pasatiempos y a las novelas cortas que contiene dedica Aguilar Piñal 1987 unas páginas relativas a su repertorio temático, a sus fuentes y modelos y a la presencia de asuntos orientales y de historia nacional.

\section{- Antonio VALLADARES de SOTOMAYOR}

Herrera Navarro 1986 considera La Leandra un intento de aclimatación de la novela inglesa al estilo de Richardson, resuelto como síntesis de novela cortesana ampliada, novela epistolar, novela bizantina y novela sentimental. Esquematiza su estructura en función de dos sujetos narrativos (Aniceta y Leandra) y de las historias y subhistorias, insertas en una compleja estratigrafía que llega a alcanzar una articulación en cuatro niveles. Pone de manifiesto la gama temática manejada por Valladares, el singular atractivo del anecdotario referente al mundillo teatral de la época, y la caracterización sentimental de los personajes; y estudia las ideas literarias del prólogo en cuanto a concepto de novela, conciencia de la técnica narrativa y requisitos de calidad.

García Garrosa 1993, tras incidir en parecidas consideraciones y plantear la posible existencia de un volumen $X$, remate del texto inacabado que ha llegado hasta nosotros, insiste en la estructura abierta de La Leandra y señala sus defectos y su posible justificación: fomentar la venta de una serie potencialmente ilimitada de volúmenes, a modo de novela por entregas.

Véase Román Gutiérrez 1988, pp. 100-102. 


\section{- Gaspar ZAVALA y ZAMORA}

Véase Carnero 1988 y el estudio preliminar a Zavala 1992.

\section{UNA CONSIDERACIÓN FINAL}

No creo que deba entrar en mi recuento la edición, por Eugenio Cobo y Fernando R. de la Flor (1987), de la Historia de la cuevas de Salamanca de Botello de Moraes, dada la índole de esta obra, llena de atractivo por otra parte. Ante el caso de Alonso CARRIÓ DE LA VANDERA, y por si alguien lo echara de menos aquí, me limitaré a señalar la recopilación bibliográfica de Woodbridge 1990 y los artículos de Zapata 1990, Fernández Insuela 1990 b, Díaz-José Blanco 1993, Rodrigo 1993 y Wentzlaff-Eggebert 1993. El primero trata de las ideas de Carrió sobre mejora de la productividad, de las comunicaciones y de la educación, y de su mentalidad colonialista y visión de indios, mestizos y negros, además de relacionar el Lazarillo con la literatura de viajes del siglo XVIII. El segundo aclara la adivinanza folklórica de "las cuatro PPPP de Lima" a la vista de su presencia en Tertulia de la aldea, y en Deleite de la discreción de Bernardino Fernández de Velasco. El último pone el acento en la observación por Carrió de las peculiaridades geográficas, económicas, urbanísticas y antropológicas en su viaje entre Buenos Aires y Lima.

\section{CONCLUSIONES}

Quien me haya seguido hasta aquí, a pesar de la forzada monotonía de estas páginas, las habrá sacado por sí mismo. Continúa el goteo de estudios sobre Torres e Isla, y la presencia de sus obras en librería y en colecciones destinadas a la enseñanza. El último decenio ha presenciado una notable y renovadora ampliación del ámbito de la novela española del XVIII, gracias a la recuperación de siete autores (García Malo, Gutiérrez, Martínez Colomer, Montengón, Olavide, Tójar, Zavala y Zamora) y la publicación de una veintena larga de obras, olvidadas o inasequibles. Han salido a la luz más de cien trabajos de investigación sobre novelistas desatendidos por la historiografía y la crítica, y comienza a normalizarse su presencia en los manuales de Historia de la Literatura Española. Numerosos investigadores jóvenes dirigen su esfuerzo hacia nuestra novela dieciochesca, en buena parte inexplorada todavía. La situación actual es altamente esperanzadora y positiva, y obliga a arrumbar el tópico del supuesto "vacío novelístico" de la España del XVIII. 


\section{OBRAS CITADAS}

\section{Ediciones de textos clásicos}

José F. de ISLA. 1991. Fray Gerundio, ed. J. Álvarez Barrientos, Barcelona, Planeta. Estudio preliminar de $41 \mathrm{pp}$.

- 1992 a. Fray Gerundio, ed. J. Jurado, Madrid, Gredos. Estudio preliminar de 65 pp.

- 1992 b. Fray Gerundio, ed. R.P. Sebold, Madrid, Espasa-Calpe, 2 vols. Estudio preliminar de $83 \mathrm{pp}$.

Diego de TORRES VILLARROEL. 1985 a. Vida, ed. R.P. SEBOLD, Madrid, Taurus. Estudio preliminar de $94 \mathrm{pp}$.

- 1985 b. Vida, ed. A. Aranda, Salamanca, Caja de Ahorros. Prólogo de G. Torrente Ballester, 1 pág.

— 1989. Vida, ed. M. PÉrez López, Madrid, Espasa-Calpe. Estudio preliminar de 47 pp.

\section{Ediciones de textos recuperados}

Ignacio GARCÍA MALO. 1995. Voz de la Naturaleza, ed. G. CARNero, Londres, Tamesis \& Fund. Juan March \& Universidad de Alicante. 393 pp. Estudio preliminar de 127 pp.

[Luis GUTIÉRREZ]. 1987. Cornelia Bororquia, ed. G. Dufour, Alicante, Instituto Juan GilAlbert. 214 pp. Estudio preliminar de 47 pp.

- 1994. Cornelia Bororquia, ed. J.I. Ferreras, Madrid, VOSA. 145 pp. Estudio preliminar de $24 \mathrm{pp}$.

José F. de ISLA. 1989. Apología por la Historía de Fray Gerundio, ed. J. Jurado, Madrid, F.U.E. 176 pp. Estudio preliminar de 22 pp.

Vicente MARTÍNEZ COLOMER. 1985. El Valdemaro, ed. G. CARNERO, Alicante, Instituto Juan Gil-Albert. 257 pp. Estudio preliminar de $38 \mathrm{pp}$.

Pedro MONTENGÓN. 1990. El Rodrigo. Eudoxia, hija de Belisario. Selección de Odas, ed. G. Carnero, Alicante, Instituto Juan Gil-Albert, 2 vols. $475+358$ pp. Estudio preliminar de $204 \mathrm{pp}$.

Pablo de OLAVIDE. 1987. Obras selectas, ed. E. Núñez, Lima, Banco de Crédito del Perú. $225 \mathrm{pp}$. dedicadas a la obra narrativa. Estudio preliminar de $92 \mathrm{pp}$.

Francisco de TÓJAR. 1995. Cuentos morales. La filósofa por amor, ed. J. Álvarez Barrientos. Cádiz, Universidad -en prensa.

Gaspar ZAVALA y ZAMORA. 1992. Obras narrativas: La Eumenia. Oderay, ed. G. CARNero, Barcelona, Sirmio \& Universidad de Alicante. 269 pp. Estudio preliminar de $47 \mathrm{pp}$.

\section{Misceláneas}

VV.AA. 1993. Madrid en la novela, 1700-1850, ed. J. Álvarez Barrientos, Madrid, Comunidad de Madrid. Estudio preliminar de $8 \mathrm{pp}$.

Diego de TORRES VILLARROEL. 1994. Prosa narrativa, ed. M. Pérez López, Madrid, Confederación Española de Gremios y Asociaciones de Libreros. Estudio preliminar de 4 pp. 


\section{Estudios}

AGUILAR PIÑAL. Francisco. 1981-1993. Bibliografía de autores españoles del siglo XVIII, Madrid, C.S.I.C., 7 vols.

- 1987 a. "La continuación de La Galatea por Trigueros", Dicenda 6, pp. 334-341.

- 1987 b. Un escritor ilustrado: Cándido Ma Trigueros. Madrid, C.S.I.C.,pp. 255-263.

- 1992. "La novela que vino del Norte", Ínsula 546, pp. 9-10.

ALONSO SEOANE, M José. 1984. "La obra narrativa de Pablo de Olavide", Axerquía 11, pp. 11-49.

- 1985 a. "Las novelas de Olavide" en Las Nuevas Poblaciones de Carlos III en Sierra Morena y Andalucía, Córdoba, Universidad, pp. 363-372.

- 1985 b. "Los autores de tres novelas de Olavide", en Andalucía y América en el siglo XVIII, II, Sevilla, Escuela de Estudios Hispanoamericanos, pp. 1-22.

- 1986. "Algunos aspectos de las ideas ilustradas de Olavide en las Lecturas útiles y entretenidas". Alfinge 4, pp. 215-228.

- 1988 a. "Una adaptación española de Blanchard: El sepulcro en el monte de Vicente Rodríguez de Arellano", Crisol 8, pp. 6-19.

- 1988 b. "Una desconocida traducción española de L. D'Ussieux: La heroína francesa de Vicente Rodríguez de Arellano", Investigación Franco-Española 1, pp. 9-30.

- 1988 c. "Un texto del Inca Garcilaso y la novela F ederico y Beatriz de Ignacio García Malo", en Actas Congreso Internacional de Historia de América, II, Córdoba, Universidad, pp. 141-151.

- 1988 d. "Dos principios ilustrados en las últimas obras literarias de Olavide", en Carlos III y las Nuevas Poblaciones, III, Córdoba, Universidad, pp. 281-298.

- 1989. "Una versión desconocida de la novela de Blanchard Félix et Pauline, ou Le tombeau au pied du Mont Jura", en Actas VI Simposio Sociedad Española de Literatura General y Comparada, Granada, Universidad, pp. 231-237.

- 1990. "La novela en el Correo literario de la Europa", en Periodismo ellustración en España, extraordinario de Estudios de Historia Social n 52-53, pp. 23-28.

- 1991. "Adaptaciones narrativas en el siglo XVIII español. El amor desinteresado de Pablo de Olavide", en Traducción y adaptación cultural España-Francia, Oviedo, Universidad, pp. 199-210.

— 1992. "Olavide adaptador de novelas: una versión desconocida de Germeuil de Baculard d'Arnaud", en Actas X Congreso Internacional de Hispanistas, II, Barcelona, P.P.U., pp. 1157-1166.

- 1993. "Los originales presentados a censura de las Lecturas útiles y entretenidas", Entresiglos 2, pp. 21-30.

- 1995 a. "Francia en la obra narrativa de Pablo de Olavide", en L'Image de la France en Espagne pendant la seconde moitié duXVIIle. siècle, París, C.R.O.D.E.C.-Université de Paris III -en prensa-.

-- 1995 b. "Teatro y novela en el último período de la Ilustración", en Actas Congreso Internacional sobre Teatro Español del Siglo XVIII, Lérida, Universidad —n prensa-.

ÁLVAREZ BARRIENTOS, Joaquín. 1987-1988. "Sobre la institucionalización de la literatura: Cervantes y la novela en las historias literarias del siglo XVIII", Anales Cervantinos XXV-XXVI, extraordinario Homenaje a Alberto Sánchez, pp. 47-63. 
- 1989. "Controversias acerca de la autoría de varias novelas de Cervantes en el siglo XVIII...", en Actas IX Congreso Internacional de Hispanistas, I, Frankfurt, Vervuert, pp. 301-309.

- 1990. "La novela española en la época de la Revolución Francesa", en Cultura hispánica y Revolución Francesa, Roma, Bulzoni, pp. 57-73.

— 1991 a. "Preceptiva literaria española y novela (1737-1826)", Entresiglos 1, pp. 2956.

- 1991 b. La novela del siglo XVIII, Madrid, Júcar.

- 1992. "Por qué se dijo que en el siglo XVIII no hubo novela?", Ínsula 546, pp. 11 13.

- 1993. "Fernando Gutiérrez de Vegas y su novela Los enredos de un lugar (17781781)", en Art and Literature in Spain 1600-1800. Studies i.h. of Nigel Glendinning, Londres, Támesis, pp. 35-45.

- 1995 a. "Novela antigua y novela moderna en el siglo XVIII", en Novedad y tradición en la literatura del siglo XVIII, Madrid, Júcar -en prensa.

- 1995 b. "Imagen francesa y civilización en la novela española del siglo XVIII", en L'Image de la France en Espagne... -en prensa.

- 1995c. "El modelo femenino en la novela española del siglo XVIII", Hispanic Review 63, 1, pp. 1-18.

ANDIOC, René. 1991. "Un conte de Voltaire traduit par Moratín", Ibérica extraordinario Homenaje a P.J. Guinard, II, pp. 7-17.

ARAGÓN FERNÁNDEZ, Aurora. 1989. "Traducciones de obras francesas en la Gaceta de Madrid entre 1790 y $1799 "$, en Imágenes de Francia en las letras hispánicas, Barcelona, P.P.U., pp. 261-269.

- 1991. "Una teoría de la traducción en el siglo XVIII: Covarrubias", en Traducción y adaptación cultural España-Francia, Oviedo, Universidad, pp. 531-540.

ARIJA NAVARRO, Asunción. 1987.Lallustración aragonesa:Joaquín Traggia,Zaragoza, Institución Fernando el Católico.

BAQUERO ESCUDERO, Ana L. 1988. Una aproximación neoclásica al género "novela". Clemencín y el Quijote, Murcia, Academia Alfonso el Sabio.

BARRERO PÉREZ, Óscar. 1986. "Los imitadores y continuadores del Quijote en la novela española del siglo XVIII", Anales Cervantinos XXIV, pp. 103-121.

BERMÚDEZ CAÑETE, Federico. 1989. "Notas sobre la influencia de Rousseau en España", en Homenaje a Antonio Gallego Morell, I, Granada, Universidad, pp. 209-222.

BRIESEMEISTER, Dietrich. 1986 a. "La aventura de leer en Fray Gerundio", Ibero Romania XXIII, pp. 125-148.

— 1986 b. "José Francisco de Isla: Historia del famoso predicador Fray Gerundio de Campazas...", en V. Roloff \& H. Wentzlaff-Eggebert (eds.), Der Spanische Roman von Mittelalter bis zur Genenwart, Dusseldor, Schwann Bagel, pp. 171-192.

CARNERO, Guillermo. 1985. "Un novelista sensible de finales del siglo XVIII: Vicente Martínez Colomer", Il Confronto Letterario II, 4, pp. 335-345.

- 1988. "Sensibilidad y exotismo en un novelista entre dos siglos: Gaspar Zavala y Zamora", Romanticismo 3-4, pp. 23-29. 
- 1990. "Las Memorias literarias de París y la supuesta modernidad de Ignacio de Luzán ante la ciencia y la literatura de su tiempo", en Europa en España. España en Europa, Barcelona, P.P.U., pp. 63-81.

- 1993. "La Holandesa de Gaspar Zavala y Zamora y la literatura gótica del XVIII español", en Ex Libris. Homenaje a José Fradejas Lebrero, II, Madrid, U.N.E.D., pp. 517-539.

- 1995 a. "La leyenda del último godo y el romanticismo de Pedro Montengón", en L. LÓPEZ-BARALT \& F. MÁRQUez villanueva (eds.), Erotismo en las letras hispánicas, México, El Colegio de México, pp. 33-46.

- 1995 b. "Datos para la biografía del novelista dieciochesco Ignacio García Malo", Hispanic Review -en prensa.

- 1995 c. "Fuentes de la obra narrativa de Ignacio García Malo", en Homenaje a Francisco Aguilar Piñal -en prensa.

— 1995 d. "Ignacio García Malo y su actividad de traductor", en Homenaje a M" Jesús Rubiera -en prensa.

- 1995 e. "La obra de tema político de Ignacio García Malo", en Homenaje a Rinaldo Froldi -en prensa.

- 1995 f. "Una atribución infundada a Ignacio García Malo: La Voz de la Naturaleza sobre el origen de los gobiernos", en Homenaje a Javier Herrero -en prensa.

- 1995 g. "François-Thomas de Baculard d'Arnaud y Gaspar Zavala y Zamora: la fuente de Las víctimas del amor", en Homenaje a José Luis Varela -en prensa.

CARNERO, Guillermo (ed.). 1991. Montengón, Alicante, Caja de Ahorros Provincial.

CHECA BELTRÁN, José. 1992. "Novela y teoría española dieciochista", Ínsula 546, pp. 15-17.

CHEN SHAM, Jorge. 1990. "Pour une lecture sociocritique de Fray Gerundio de Campazas...", Imprévue 2, pp. 133-138.

CRUZ CASADO, Antonio. 1988. "El viaje como estructura narrativa: Los trabajos de Narciso y Filomela de Vicente Martínez Colomer, una novela inédita", Dieciocho 7, pp. 309-325.

-1 1992. "Un curioso relato intercalado: las aventuras del pícaro Luis en la Historia de Liseno y Fenisa", en El relato intercalado, Madrid, Fundación Juan March \& Sociedad Española de Literatura General y Comparada, pp. 119-129.

DELGADO GÓMEZ, Ángel. 1986. "La autobiografía como juego publicitario: la Vida de Torres Villarroel”, Crisol 4, pp. 57-88.

DIÁZ-JOSÉ BLANCO, Santiago. 1993. "Alonso Carrió de La Vandera, "Concolorcorvo": el contexto migratorio de su época y lugar de origen", Revista de Indias LIII, 198, pp. 639-650.

DOMERGUE, Lucienne. 1985. "Ilustración y novela en la España de Carlos IV", en Homenaje a José A. Maravall, I, Madrid, Centro Investigaciones Sociológicas, pp. 483-498.

DUFOUR, Gérard. 1987. "Andanzas y muerte de Luis Guitérrez, autor de la novela Cornelia Bororquia”, Caligrama II, 2, pp. 83-96.

- 1993. "Le origini dell'anticlericalismo in Spagna nell'epoca contemporanea", en A. Mola (ed.), Stato, Chiesa e società in Italia, Francia, Belgio e Spagna nei secoli XIX$X X$, Foggia, Bastogi, pp. 57-63.

EMIEUX, Annick. 1985. "De Bonola à Montengón, et d'une hérésie à l'autre", Ibérica V, pp. 147-158. 
- 1988. "Le thème alimentaire dans un roman du XVIIIe. siècle: Eusebio", en Mélanges offerts à Maurice Molho, I, extraordinario de Ibérica, pp. 247-262.

- 1991. "Un roman qui cherche sa forme: le manuscrit de l'Eudamonopeia du P. Joaquín Traggia", extraordinario de Ibérica Homenaje a P.J. Guinard, II, pp. 97-108.

ERTLER, Klaus. 1989. "Cervantes und Blanco-White...", Ibero Romania 29, pp. 65-80.

ESCOBAR, José. 1992. "Costumbrismo y novela: el costumbrismo como materia novelable en el siglo XVIII”, Ínsula 546, pp. 17-19.

FABBRI, Maurizio. 1985. "Utopías posibles al acabar un siglo: Montengón y Thjulén”, en Homenaje a José A. Maravall, II, Madrid, Centro Investigaciones Sociológicas, pp. 6578.

- 1992. "I gesuiti espulsi in Italia e la polemica sulla tradizione poetica spagnola. L'opera di Giambattista Conti", en Italia e Spagna nella cultura del'700, Roma, Academia Nazionale dei Lincei, pp. 145-162.

FERNÁNDEZ CIFUENTES, Luis. 1994. "Historia literaria y placer de la lectura: la canonización de Torres Villarroel”, Siglo XX/20th. Century, pp. 87-111.

FERNÁNDEZ GÓMEZ, Juan \& NIETO FERNÁNDEZ, Natividad, 1991. "Tendencias de la traducción de obras francesas en el siglo XVIII", en Traducción y adaptación cultural España-Francia, Oviedo, Universidad, pp. 579-591.

FERNÁNDEZ GONZÁLEZ, Ángel R. 1990. "Pablo de Olavide, traductor y adaptador de obras dramáticas y narrativas francesas", en Europa en España. España en Europa, Barcelona, P.P.U., pp. 93-104.

FERNÁNDEZ INSUELA, Antonio. 1986. "Opiniones sobre Inglaterra en el Quixote de la Cantabria", en Scripta i.m.J.B. Álvarez Buylla, Oviedo, Universidad, pp. 161-167.

- 1990 a. "Notas sobre la narrativa breve en las publicaciones periódicas del siglo XVIII: estudio de la Tertulia de la Aldea", en Periodismo e Ilustración en España, pp. $181-194$.

- 1990 b. "Un dato sobre un enigma del Lazarillo de ciegos caminantes", Bulletin Hispanique 92, 2, pp. 847-856.

- 1993. "Sobre la narrativa española de la Edad de Oro y sus reediciones en el siglo XVIII", Revista de Literatura LV, 109, pp. 55-84.

- 1995 a. "Consideraciones sobre Ribero y Larrea y la Ilustración", en Homenaje a José Caso González -en prensa.

— 1995 b. "Elementos tradicionales y clásicos en un manuscrito de 1811 ", en Homenaje a Cristóhal Rodríguez Alonso, Oviedo, Universidad -en prensa.

- 1995 c. "Textos para la historia del cuento tradicional en el siglo XVIII", en Homenaje a Francisco Aguilar Piñal -en prensa.

FERRERAS, Juan I. 1987. La novela en el siglo XVIII, Madrid, Taurus.

FREIRE LÓPEZ, Ana M". 1989. "Un traductor del reinado de Carlos III: Bernardo M"a de Calzada", Investigación Franco-Española 2, pp. 71-80.

GARCÍA GARROSA, M" Jesús. 1991. "Dos nuevas versiones españolas del Décaméron François", Investigación Franco-Española 5, pp.113-129.

- 1992 a. "Valladares, adaptador de Marmontel. Una nueva versión española de los Contes Moraux", Investigación Franco-Española 7, pp. 39-54. 
- 1992 b. "ElConde de Comminge: fortuna literaria de un mito dieciochesco en Francia y España”, Epos VIII, pp. 353-375.

- 1993. "La Leandra...", Boletín Biblioteca Menéndez Pelayo LXIX, pp. 143-165.

GARCÍA LARA, Fernando. 1992. "Materiales novelescos en la primera mitad del siglo XVIII", Ínsula 546, pp. 13-14.

GIMÉNEZ LÓPEZ, Enrique. 1993. "El Ejército y la Marina en la expulsión de los jesuitas de España”, Hispania Sacra 45, pp. 577-630.

GÓMEZ NAVARRO, Soledad. 1986-1987. “... Notas para el estudio de la muerte a través de las novelas de Olavide y Montengón", Ifigea III-IV, pp. 147-176.

GUINARD, Paul J. 1990. "Aspects utopiques dans le roman espagnol de la fin du XVIIIe. siècle", en Las utopías en el mundo hispánico, Madrid, Casa de Velázquez \& Universidad Complutense, pp. 57-63.

GUMBRECHT, Hans U. 1986. "Vida [...] del Dr. Diego de Torres Villarroel...", en Der Spanische Roman von Mittelalter bis zur Genenwart, cit. pp. 145-170.

HAFTER, Monroe Z. 1986. "Mor's achievement of realism in La Serafina", Dieciocho 9, pp. 153-163.

- 1991. "Montengón's El Mirtilo in its XVIIIth. Century context", Bulletin of Hispanic Studies LXVIII, 1, extraordinario Homenaje I. McClelland, pp. 37-46.

- 1993. "Two perspectives on self in Spanish autobiography (1743-1845)", Dieciocho $16,1-2$, pp. 77-94.

HERRERA NAVARRO, Jerónimo. 1986. "La Leandra...", en Homenaje a Luis Morales Oliver, Madrid, F.U.E., pp. 623-641.

ILIE, Paul. 1986. "Dream cognition and the Spanish Enlightenment: judging Torres Villarroel", Modern Languaje Notes 101, pp. 270-297.

JURADO, José. 1985. "Ediciones tempranas del Fray Gerundio de Campazas", Bulletin Hispanique 87, pp. 137-165.

- 1989. "El Fray Gerundio y la oratoria sagrada barroca". Edad de Oro VIII, pp. 97 105.

LAFARGA, Francisco. 1988. "Sobre recepción de la narrativa francesa del siglo XVIII en España: los intermediario", en Narrativa francesa del siglo XVIII, Madrid, U.N.E.D., pp. $429-438$.

LOPEZ, François. 1988. "De la Célestine au Quichotte: histoire et poétique dans l'oeuvre de Mayans", Bulletin Hispanique XC, pp. 215-429.

- 1990. "Las obras extranjeras anunciadas en la Gaceta de Madrid...", en Periodismo ellustración en España, extraordinario de Estudios de Historia Social, 52-53, pp. 303311.

MARTÍNEZ DE LA ESCALERA, José. 1986. "Isla ante Feijoo", en Homenaje a Pedro Sainz Rodríguez, III, Madrid, F.U.E., pp. 471-486.

MERCADIER, Guy. 1988. "Dans le sillage de l'autobiographie torrèsienne...", en Ecrire sur soi en Espagne, Aix, Universidad, 1988, pp. 117-135.

MEREGALLI, Franco. 1993. "Los dos primeros siglos de recepción de la obra cervantina", en Actas III Coloquio Internacional Asociación de Cervantistas, Barcelona, Anthropos, pp. 33-42. 
NÚÑEZ, Estuardo. 1988. "Una novela desconocida de Pablo de Olavide", Cuadernos Hispanoamericanos 459, pp. 125-129.

PAGEARD, Robert. 1993. "La traduction espagnole de Werther par José Mor de Fuentes (1885). À propos d'une réedition", Revue de Littérature Comparée 2, pp. 267-274.

PAJARES, Eterio. 1991. "Influencias de la narrativa lacrimosa inglesa en Eusebio y Eudoxia de Montengón”, Bulletin Hispanique 93, pp. 353-364.

- 1992. "Influencia de la narrativa lacrimosa europea en las novelas cortas de Olavide", Archivum 39-40, pp. 385-394.

PALOMO, Pilar. 1986. "Gracián y la novela del siglo XVIII: el Criticón y el Euscbio", en Gracián y su época, Zaragoza, Institución Fernando el Católico, pp. 375-388.

PENSADO, José L. 1987. "Servidumbre y libertad en Fr. Martín Sarmiento y su Noticia de la verdadera patria de D. Miguel de Cervantes", en De la llustración al Romanticismo, Cádiz, Universidad, pp. 109-124.

PEÑA VELASCO, Concepción. 1985. Aspectos biográficos y literarios de Diego Antonio Rejón de Silva, Murcia, Conserjería de Cultura et al.

PÉREZ LÓPEZ, Manuel. 1995. "Para una revisión de Torres Villarroel", en Novedad y tradición en la literatura del siglo XVIII, Madrid, Júcar \& Valladolid, Universidad -en prensa.

PÉREZ MAGALLÓN, Jesús. 1986-1987. "Una teoría dieciochesca de la novela y algunos conceptos de poética”, Anales de Literatura Española 5, pp. 357-376.

- 1990. "La crítica literaria dieciochesca: Mayans y Siscar", Boletín Biblioteca Menéndez Pelayo LXVI, pp. 111-130

- 1991. En torno a las ideas literarias de Mayans, Alicante, Instituto Juan Gil-Albert.

- (ed.). 1994. Gregorio Mayans, Escritos literarios, Madrid, Taurus.

PÉREZ RIOJA, José A. 1988. "Un best-seller del siglo XVIII: Ia novela Eusebio de Montengón", en El Madrid de Carlos III, Madrid, Ayuntamiento.

PHILIPPOT ARCAIX, Jannick. 1986. "El Dr. D. Diego de Torres Villarroel. Presentación de dos testamentos inéditos", Salamanca. Revista Provincial de Estudios, 20-21, pp. $125-146$.

PICARD, Hans R. 1988. "Le role de locura et razón en tant que forces antithétiques dans la genèse d'une autobiographie moderne: la Vida de Torres Villarroel", en Écrire sur soi en Espagne, Aix, Universidad, pp. 105-115.

PRECEDO LAFUENTE, Manuel. 1988. "Citas bíblicas en los sermones de Fray Gerundio de Campazas", Compostellanum XXXIII, pp. 247-280.

RIPOLL, Begoña \& DE LA FLOR, Fernando R. 1991. "Los cien libros de novelas, cuentos, historias y casos trágicos de Pedro Joseph Alonso y Padilla", Criticón 51, pp. 75-97.

RODRIGO, Enrique. 1993. "Carrió de La Vandera y Feijoo: el papel de la historia en el exordio de El Lazarillo de ciegos caminantes", Boletín Instituto Estudios Asturianos 47 (1993), pp. 259-268.

RODRÍGUEZ, Rodney. 1985. "Continuity and innovation in the Spanish novel, 1700-1833", en Homenaje a John Dowling, Newark, Juan de la Cuesta, pp. 49-63.

- 1989. "Literatura oral y subdesarrollo novelístico: un fenómeno del XVIII español", en Actas IX Congreso Internacional de Hispanistas, Frankfurt, Vervuert, II, pp. 85-90. 
RODRÍGUEZ CEPEDA, Enrique. 1988 a. "Los Quijotes del siglo XVIII: 1. La Imprenta de Manuel Martín”, Cervantes VIII, pp. 61-108.

- 1988 b. "Los Quijotes del siglo XVIII: 2. La Imprenta de Juan Jolis", Hispania 71, pp. 752-779.

- 1992. "Sobre el Quijote en la novela del siglo XVIII español", Ínsula 546, pp. 1920.

RODRÍGUEZ PAZOS, Manuel. 1985. "El P. Isla y Fray Gerundio..." Liceo Franciscano XXXVIII, pp. 167-200.

ROMÁN GUTIÉRREZ, Isabel. 1988. Persona y forma: Una historia interna de la novela española del siglo XIX, I, Sevilla, Alfar, pp. 67-123.

RUGGERI MARCHETTI, Magda. 1986. Studio su "La Serafina" di José Mor de Fuentes, Roma, Bulzoni.

SÁNCHEZ GARCÍA, M" Carmen. 1987. "Santiváñez y la teoría de la novela en el siglo XVIII", Kultura 11, pp. 125-140.

SEBOLD, Russell P. 1992. "Montengón y la novela romántica", De ilustrados y románticos, Madrid, El Museo Universal, pp. 103-108.

SOUBEYROUX, Jacques. 1988. "Sátira y utopía de la Corte en Aventuras de Juan Luis de Rejón y Lucas (1781)", en Carlos III, Madrid y la Ilustración, Madrid, Siglo XXI, pp. 379-417.

— 1991. "Syntaxe narrative et statut des personnages dans Aventuras de Juan Luis (1781) de Rejón y Lucas", Ibérica extraordinario Homenaje P.J. Guinard, II, pp. 205218.

TIETZ, Manfred. 1992. "El proceso de secularización y la problemática de la novela en el siglo XVIII", en La secularización de la cultura española en el Siglo de las Luces, Weisbaden, Harrassowitz, pp. 227-246.

TRUXA, Sylvia. 1990. "L'eroe nel romanzo sentimentale spagnolo ed in altre letterature", en Il romanzo sentimentale (1740-1814), Pordenone, Studio Tesi, pp. 139-168.

- 1995. "La bella sin rostro en la novela sentimental del siglo XVIII", en Homenaje a Francisco Aguilar Piñal -en prensa.

URRUTIA, Jorge. 1990. "El inicio de la novela anticlerical", en Cultura hispánica y Revolución Francesa, Roma, Bulzoni, pp. 75-86.

URZAINQUI, Inmaculada. 1986. "Anuncios y reseñas de traducciones de obras inglesas en la prensa española del siglo XVIII", en Scripta i.m. J.B. Álvarez Buylla, Oviedo, Universidad, pp. 313-332.

- 1991. "Hacia una tipología de la traducción en el siglo XVIII: los horizontes del traductor", en Traducción y adaptación cultural España-Francia, Oviedo, Universidad, pp. 623-638.

WENTZLAFF-EGGEBERT, Christian. 1993. "Una obra hispanoamericana entre Ilustración y costumbrismo: el Lazarillo de ciegos caminantes", Entresiglos 2, pp. 259-268.

WOODBRIDGE, Hensley C. 1990. "Recent studies on Alonso Carrió de La Vandera: a bibliographical essay", Dieciocho 13, pp. 50-57.

ZAPATA, Roger A. 1990. "El Otro del Lazarillo", Dieciocho 13, pp. 58-70.

ZAVALA, Iris M. 1987. Lecturas y lectores del discurso narrativo dieciochesco, Amsterdam, Rodopi.

- 1992. "Isla, la parodia sacra y la cultura de la risa", en La secularización de la cultura española... pp. 287-299. 